\title{
Burkholderia vaccines: are we moving forward?
}

\section{Leang-Chung Choh, Guang-Han Ong, Kumutha M. Vellasamy, Kaveena Kalaiselvam, Wen-Tyng Kang, Anis R. Al-Maleki, Vanitha Mariappan and Jamuna Vadivelu*}

Department of Medical Microbiology, Faculty of Medicine, University of Malaya, Kuala Lumpur, Malaysia

Edited by:

Mark Estes, University of Georgia, USA

\section{Reviewed by:}

William Picking, Oklahoma State

University, USA

Chad J. Roy, Tulane University, USA

\section{${ }^{*}$ Correspondence:}

Jamuna Vadivelu, Department of Medical Microbiology, Faculty of Medicine, University of Malaya, 50603 Kuala Lumpur, Malaysia. e-mail: jamuna@ummc.edu.my
The genus Burkholderia consists of diverse species which includes both "friends" and "foes." Some of the "friendly" Burkholderia spp. are extensively used in the biotechnological and agricultural industry for bioremediation and biocontrol. However, several members of the genus including B. pseudomallei, B. mallei, and B. cepacia, are known to cause fatal disease in both humans and animals. B. pseudomallei and B. mallei are the causative agents of melioidosis and glanders, respectively, while B. cepacia infection is lethal to cystic fibrosis (CF) patients. Due to the high rate of infectivity and intrinsic resistance to many commonly used antibiotics, together with high mortality rate, B. mallei and B. pseudomallei are considered to be potential biological warfare agents. Treatments of the infections caused by these bacteria are often unsuccessful with frequent relapse of the infection. Thus, we are at a crucial stage of the need for Burkholderia vaccines. Although the search for a prophylactic therapy candidate continues, to date development of vaccines has not advanced beyond research to human clinical trials. In this article, we review the current research on development of safe vaccines with high efficacy against B. pseudomallei, B. mallei, and B. cepacia. It can be concluded that further research will enable elucidation of the potential benefits and risks of Burkholderia vaccines.

Keywords: Burkholderia pseudomallei, Burkholderia mallei, Burkholderia cepacia, melioidosis, glanders, cystic fibrosis, vaccine

\section{Burkholderia spp.}

The genus Burkholderia is a phylogenetically coherent genus consisting of interesting and complex bacterial taxonomy which includes a wide variety of Gram-negative, bacilli ( $1-5 \mu \mathrm{m}$ length and $0.5-1.0 \mu \mathrm{m}$ width), that are motile due to the presence of multi-trichous polar flagella (Vandamme et al., 2007). These bacteria are generally obligate aerobes and commonly found in the soils of all temperatures including the Arctic soil at temperature of $7^{\circ} \mathrm{C}$ (Master and Mohn, 1998) and in groundwater worldwide (Ussery et al., 2009). The genomic G + C content of Burkholderia spp. ranges between $64 \%$ and $68.3 \%$ (Yabuuchi et al., 1992). Members of the genus Burkholderia were formerly classified as belonging to the genus of Pseudomonas which belongs to the Proteobacteria homology group II (Yabuuchi et al., 1992). The taxonomy of the genus Burkholderia has undergone considerable changes since it was first reported, when 22 validly described species were included (Coenye et al., 2001). Currently, the Burkholderia genus comprises at least 43 species, which are extremely diverse and versatile (Vial et al., 2007; Compant et al., 2008).

Members of the genus Burkholderia can form associations with plants and are also able to cause disease in animals and humans. There are two main factors that can be attributed to the ecological versatility of the members of this genus which includes: (1) the huge coding capacity of their large multireplicon genomes $(6-9 \mathrm{Mb})$ that allow the members of the genus to be metabolically robust; and (2) an array of insertion sequences in their genomes which promote genomic plasticity and general adaptability (Lessie et al., 1996). Their survival and persistence, in the environment and in host cells, offers a notable example of bacterial adaptation (Woods and Sokol, 2006).

Several members of the genus are used in a variety of biotechnological applications, including bioremediation, biological control of plant diseases, water management, and also improvement of nitrogen fixation (Parke and Gurian-Sherman, 2001). Although most of the species in the genus Burkholderia are not pathogenic for healthy individuals, a few that include B. pseudomallei, B. mallei, and B. cepacia, are capable of causing severe, life-threatening infections in both normal and immunocompromised individuals. Some of these infections are inherently difficult to treat due to the resistance of these bacteria to multiple antibiotics, the ability to form biofilms, and the establishment of intracellular and chronic infection stages in the host (George et al., 2009).

Preventive measures such as the use of vaccines for active immunization could offer significant protection to persons living in endemic areas and reduce the worldwide incidence of Burkholderia infections. In addition, the range of infections caused by Burkholderia spp. and the potential to develop chronic infections in the immunocompromised host through the persistent nature of these bacteria makes the need for a vaccine crucial. In recent years, many studies have been performed in order to identify vaccine strategies against $B$. pseudomallei, B. mallei, and B. cepacia, but to date no ideal candidate has yet emerged (Sarkar-Tyson and Titball, 2010). The most important reason for the failure to identify a good vaccine is due in the main to the 
intracellular nature of these pathogens which makes it difficult to evoke both an antibody response and also strong cellular-based responses.

\section{Burkholderia pseudomallei}

B. pseudomallei is endemic in the soils of southeast Asia and northern Australia and have been reported to occur in other tropical and subtropical regions, worldwide. The bacterium is now classified as Category B priority agent and the disease caused is known as melioidosis which was first described as a "glanders-like" disease among morphine addicts by Whitmore and Krishnasawami in Rangoon, Burma in 1911 (Whitmore, 1913; Whitmore and Krishnaswami, 2012).

Melioidosis presents as a broad range of conditions from acute fulminant pneumonia and septicemia acquired by inhalation to wound infections acquired through inoculation of the bacteria from soil through skin abrasion (Currie et al., 2000; Dance, 2002). $B$. pseudomallei also poses a worldwide emerging infectious disease problem and a bioterrorism threat due to its severe course of infection, aerosol infectivity, low infectious dose, an intrinsic resistance to commonly used antibiotics, lack of a currently available vaccine, and the worldwide availability (Stevens et al., 2004).

Pathogenesis of the disease has been demonstrated to include the ability of $B$. pseudomallei to escape into the cytoplasm from endocytic vacuoles of the host cells, where it can polymerize actin and subsequently spread from one cell to another (Kespichayawattana et al., 2000; Breitbach et al., 2003; Stevens et al., 2005; Boddey et al., 2007). A major feature of this bacterium is the ability to remain latent in the host and cause recrudescent or relapsing infections following many years past the initial infection. This relapse of the infection is quite common despite appropriate antibiotic therapy and the presence of high antibody titers in infected patients (Currie et al., 2000; Vasu et al., 2003). Regardless of antibiotic therapy, rapid progress of acute melioidosis to sepsis, followed by death within $48 \mathrm{~h}$ of clinical onset has been reported (Cheng et al., 2007). Mortality rate of patients with septic shock is reported to be approximately 80-95\% (Leelarasamee, 2004).

\section{Burkholderia thailandensis}

B. thailandensis is a closely related yet distinct B. pseudomallei-like organism (Brett et al., 1998). Although there is 99\% similarity of $B$. thailandensis genes with its virulent counterpart, the pathogenic species B. pseudomallei, it is apparently non-pathogenic in humans. Smith et al. (1997) have reported that $B$. thailandensis demonstrated a mean $50 \%$ lethal dose of $10^{9} \mathrm{cfu} /$ mouse compared to $182 \mathrm{cfu} /$ mouse for B. pseudomallei, indicating that it is also much less virulent in animal models. The avirulent properties of $B$. thailandensis might be attributed to the presence of a complete arabinose biosynthesis operon, which is an anti-virulence property and this is largely deleted in the B. pseudomallei genome (Moore et al., 2004; Lazar Adler et al., 2009). However, like B. pseudomallei, B. thailandensis also has an intracellular lifecycle. Thus, it is often used as a model microbe to study various aspects of the potential bioterrorism agent B. pseudomallei and B. mallei.

\section{Burkholderia mallei}

Glanders is caused by B. mallei which typically infects solipeds, such as horses, mules, and donkeys. $B$. mallei only occasionally infect humans such as laboratory workers and personnel who are often in close contact with infected animals (Srinivasan et al., 2001). Due to its ability to infect via inhalation route, the bacterium was among the first bioweapon used during both World Wars I and II. Since then, it has been classified as a Category B priority agent (Wheelis, 1998).

The course of infection is reliant on the route of exposure including ingestion of contaminated poultry, inhalation of aerosol containing the bacterium and abrasion which leads to a localized cutaneous infection. In an acute infection, general symptoms include fever, malaise, abscess formation, pneumonia, and sepsis. In cases of untreated septicemic infections, the fatality rate is as high as $95 \%$ whereas for antibiotic-treated individuals, 50\% fatality has been reported (Currie, 2009). Despite numerous reports that indicate in vitro susceptibility of $B$. mallei to a wide array of antibiotics, the in vivo efficacies are not wellestablished (Kenny et al., 1999; Heine et al., 2001; Judy et al., 2009). Although the pathogenic determinants of B. mallei have already been defined, the pathogenesis of the bacteria is still unknown.

\section{Burkholderia cepacia}

B. cepacia was first described as a phytopathogen with the ability to infect onion bulbs causing a condition called "soft rot" (Burkholder, 1950). The B. cepacia complex (Bcc) is a collection of closely related species which are genotypically distinct but phenotypically similar species. Strains originally identified as B. cepacia were classified into at least nine genomovars, which are referred to as the Bcc (Vandamme et al., 1997, 2000) and more recently, another eight genomovars have been included (Vanlaere et al., 2008, 2009). All Bcc species share a high degree of 16S rDNA sequence similarity (98-99\%) and moderate levels of whole genome DNA-DNA hybridization (30-50\%) (Vandamme et al., 1997, 2000; Vanlaere et al., 2009).

B. cepacia is naturally found in moist soil, particularly in the rhizosphere of plant and freshwater environments in relatively high population. It is now recognized as a significant human pathogen associated with nosocomial infections, especially among cystic fibrosis (CF) patients (Cepacia syndrome) or chronic granulomatous disease (CGD) which can lead to rapid decline of lung function. Even with proper treatment the Cepacia syndrome has been known to lead to death within a few weeks of infection. CF patients might be asymptomatic carriers of B. cepacia which over time can cause the infection to progress into a necrotizing pneumonia and bacteremia. In CF patients, $B$. cepacia infections lead on to multi-organ system dysfunction, the most severely affected being the lower respiratory tract of the affected patients. Person-to-person transmission from one $\mathrm{CF}$ patient to another via close contact in a nosocomial environment has been reported (Govan et al., 1993; Jones et al., 2004). There are also other reports suggesting the involvement of $B$. cepacia infections in cancer and HIV patients as well as among immunocompetent individuals (Marioni et al., 2006; Mann et al., 2010). B. cepacia strains have also been isolated in some cases of chronic 
suppurative otitis media, pharyngeal, and neck infections from immonocompromised individuals as reported by Marioni et al. (2006).

\section{THE NEED FOR Burkholderia VACCINES}

Vaccines against Burkholderia infections are necessary to offer prophylactic protection for susceptible large populations living in endemic areas worldwide and also for visitors to these areas (Sun et al., 2005; Suparak et al., 2005). Through vaccination, the incidence of persistent or chronic infections in the population can be reduced. As these bacteria occur in the soil, every individual has the potential risk to acquire these infections through routine daily activities.

Compounding this fact, the treatment of Burkholderia infections are especially difficult due to the inherent resistance of Burkholderia spp. to multiple antibiotics including aminoglycosides, quinolones, polymyxins, and $\beta$-lactams (Aaron et al., 2000; Martin and Mohr, 2000; Leitao et al., 2008; Estes et al., 2010). The multi-resistance property of the Burkholderia spp. may result from various efflux pumps that efficiently remove antibiotics from the cell, decreased contact of antibiotics with the bacterial cell surface due to their ability to form biofilms, and changes in the cell envelope that reduce the permeability of the membrane to the antibiotic (George et al., 2006).

Therefore, the best way to protect individuals at high risk is through the development of efficacious vaccines which are able to evoke sterilizing immunity or delay the onset of bacteremia and septic shock, to extend the window of opportunity for antibiotic treatment and still be of significant clinical benefit. To date, there is very little information available on the seroepidemiology of melioidosis in the endemic community (Finkelstein et al., 2000; Wuthiekanun et al., 2008). A seroepidemiological study performed in Khon Khean, Thailand, demonstrated that although a majority of the children were seropositive toward B. pseudomallei, none of them expressed symptoms of melioidosis, indicating the latency of B. pseudomallei in human host (Kanaphun et al., 1993). Additionally, a study conducted in Malaysia revealed seropositivity among melioidosis patients and healthy individuals (Vadivelu et al., 1995). With this existing herd immunity in endemic areas, the development of vaccines would be beneficial.

\section{HURDLES IN DEVELOPMENT OF Burkholderia VACCINES}

At present, no efficacious vaccines are available to prevent infections caused by Burkholderia spp. as none are able to achieve sterilizing immunity (Elkins et al., 2004). Despite reports on the ability of several Burkholderia vaccines to confer some immunoprotection, none of the vaccines have reached the clinical trial state indicating that there are, major difficulties that exist in the development of safe vaccines against Burkholderia infections (Elkins et al., 2004).

An important strategy to consider is the ability of the host to generate a specific immune response in the respiratory tract essentially so that it could prevent the early steps of colonization and infection by these bacteria, thus preventing or reducing lung damage due to inflammation during subsequent infections. Another dilemma in this scenario is, unlike infectious model agents, like Escherichia coli or Salmonella typhimurium, the pathogenesis of Burkholderia spp. and the specific mechanisms by which these bacteria subvert the host defense mechanisms are not well understood. Clinical manifestations of melioidosis are also varied widely from asymptomatic seroconversion, acute manifestation of septicemia, localized abscesses, disseminated infections which lead to concomitant pneumonia and multiple organ abscesses to quiescent latent infection. However, to date, the mechanisms and involvement of altered metabolism in latency is still unclear. Whether the clinical manifestations of the patient were determined by the host, pathogen, or the outcome of the interactions of both parties needs to be clarified (Gan, 2005).

To further compound this issue, Burkholderia spp. are facultative intracellular pathogens that are able to invade nonphagocytic cells which leads to the evasion of the humoral immune responses (Lazar Adler et al., 2009). Therefore, elimination of intracellular Burkholderia spp. is highly reliant on the cell-mediated immune responses. In addition, clearance of B. pseudomallei in patients has also been shown to be ineffective despite the presence of immunoglobulin $\mathrm{G}_{1}\left(\mathrm{IgG}_{1}\right)$ response, suggesting the stimulation of Th2 immune response (Puthucheary, 2009). This complicated host-pathogen interaction confers major challenges in the rational design of effective and safe vaccines for use.

Vaccine trial studies in animals have demonstrated development of immunity against Burkholderia spp. in the vaccinated animals. Despite developing immunity in animal vaccine studies, postmortem results have indicated the presence of bacteria in multi organ systems of the vaccinated animals indicating that the sterilizing immunity which is the ultimate goal of vaccine was unable to be achieved in most cases. Another proviso to these studies was the finding that experimental vaccine candidates available were only efficient in protecting against acute Burkholderia infections but not against chronic Burkholderia infections (Patel et al., 2011).

With these issues in the background and the lack of knowledge on the host-pathogen interactions being the most prominent hindrance in the development of vaccine against Burkholderia spp., to date no effective vaccines have been made available.

\section{ANIMAL MODELS FOR Burkholderia VACCINES DEVELOPMENT}

In order to study the efficacy of any vaccine, a suitable infection model is a pre-requisite. To date, although different animal models have been used for Burkholderia spp. infection studies, among the most extensively developed and described models available are those used for studies on B. pseudomallei. The models widely used for B. pseudomallei experimentation include the rodent models, especially the inbred mice strains, BALB/c and C57BL/6, and the Syrian golden hamster (Brett et al., 1997; Fritz et al., 1999; Warawa and Woods, 2005).

The use of Syrian golden hamster in Burkholderia infection and vaccines development studies are limited since it is not as well characterized as the BALB/c and C57BL/6 model. The Syrian golden hamster model is also highly susceptible to Burkholderia infection and unable to mimic human infection (Bondi and Goldberg, 2008). 
In melioidosis, it has been demonstrated clinically that release of proinflammatory cytokines in human leads to the pathological changes in acute melioidosis patients. The levels of proinflammatory cytokines also correlated with severity of acute melioidosis in patients (Wiersinga and Van Der Poll, 2009). Similarly, in BALB/c mice, a surge of proinflammatory cytokines levels peaking at 24-48 h after infection was observed. In addition, there was also poor recruitment of lymphocytes and macrophages to the infection site leading to inefficient clearance of B. pseudomallei resulting in a failure to contain the bacteria. This phenomenon, coupled with the surge of proinflammatory cytokines eventually led to extensive tissue necrosis with a high bacterial load (Lazar Adler et al., 2009). Therefore, B. pseudomallei infected-BALB/c mice highly resemble acute human melioidosis and it is a relatively suitable animal model to study the efficacy of a vaccine against acute Burkholderia infection (Macdonald and Speert, 2007).

In contrast to the $\mathrm{BALB} / \mathrm{c}$ mice, the $\mathrm{C} 57 \mathrm{BL} / 6$ exhibit lower secretion of proinflammatory cytokines levels which peaks at a later time (approximately 48-72 h). Higher rate of neutrophils and macrophages infiltration to the infection site have been observed to control the $B$. pseudomallei efficiently to prevent unrestricted spread of the bacteria in C57BL/6 (Lazar Adler et al., 2009). Lower bacterial loads were recovered from organs of infected C57BL/6 mice. These might indicate that C57BL/6 is more resistant to $B$. pseudomallei infection compared to BALB/C mice and as such, is suitable to be used as a chronic model for B. pseudomallei infection studies (Macdonald and Speert, 2007).

Long-term latency and recrudescence is one of the important features in human melioidosis which is not presented by BALB/c and C57BL/6 mice upon B. pseudomallei infection. Therefore, there is still no appropriate animal model in the study of $B$. pseudomallei latency in host. According to Titball et al. (2008), the TO outbred mice are highly resistant to $B$. pseudomallei infection and they have suggested that the TO outbred mice might be an important model to dissect the mechanisms of long-term latency of B. pseudomallei in the host. However, the use of this mouse model has not been widely adopted.

Thus, to date there is no definite suitable rodent models for research in vaccine development especially for human melioidosis. Since melioidosis demonstrates highly varied symptomatic outcome, none of the rodent models available are able to present all stages (i.e., acute, chronic, and latency states) of human melioidosis. Therefore, the lack of suitable testing models pose the major limitation in the study of the effectiveness of vaccine models against Burkholderia infections.

\section{CURRENT STRATEGIES AND DEVELOPMENT OF Burkholderia VACCINES}

Available in the literature are substantial report on development of vaccines for B. pseudomallei but far less for B. mallei and B. cepacia. It has been indicated that some of the vaccines that have been developed for melioidosis do offer cross-protection to B. mallei and B. cepacia infections (Sarkar-Tyson et al., 2009).

\section{SUBUNIT VACCINES}

Subunit vaccine took advantage of the ability of many different virulence factors of a pathogen to evoke immune responses in order to provide protection to the pathogen. However, preparation of these subunits as a vaccine require large-scale cultures of the pathogenic organism which can be hazardous due to production of aerosols and presence of large amounts of live bacteria and therefore, require extremely tight stringent safety procedures during production. This therefore led to the development of recombinant subunits as alternatives that could be delivered as purified subunit immunogens or DNA encoding the immunogens (Liljeqvist and Stahl, 1999).

\section{Burkholderia pseudomallei}

Several of the recombinant subunit candidates have been identified to protect against $B$. pseudomallei infection. The most notable candidate being LolC, an outer membrane protein (OMP) of B. pseudomallei associated with ATP-binding cassette system (Yakushi et al., 2000). Harland et al. (2007) demonstrated that $\mathrm{BALB} / \mathrm{c}$ mice immunized with recombinant LolC protein exhibited survivability rate of $80 \%$ after six weeks post-infection. Similarly, recombinant LolC protein administered with adjuvant also provided significant protection against challenge using a heterologous strain of $B$. pseudomallei containing the LolC gene. The immunization using LolC with immune-stimulating complex and CpG oligodeoxynucleotide (ODN) stimulated Th-1 type immune response. In the same study, recombinant PotF protein protected $50 \%$ of the challenged mice. Immunization with both proteins elicits a Th-1 type immune response in mice which is important in cell-mediated immune response. However, it is not clear whether sterile immunity was achieved in the surviving mice (Table 1).

Burtnick et al. (2011) identified another subunit vaccine candidate, Hcp proteins (components of the newly discovered Type 6 Secretion System), which is able to achieve a similar survivability rate as the recombinant LolC protein in the BALB/c mouse model. Six recombinant Hcp proteins (Hcp1-Hcp6) were tested for their ability to confer protection against intraperitoneal B. pseudomallei challenge and vaccination using the recombinant Hcp2 protein was found to exhibit a survival rate of $80 \%$ at 42 days post-infection (Burtnick et al., 2011). However, vaccination using Hcp 1 , Hcp3, and Hcp6 only protected $50 \%$ of the challenged mice after 42 days of infection while none of the mice immunized with Hcp4 and Hcp5 survived the challenge. It is noteworthy to mention that no bacteria were found in the spleen of the survivors immunized with Hcp1 and Hcp6 while bacteria were recovered from Hcp2-immunized survivors suggesting that sterilizing immunity is possible (Table $\mathbf{1}$ ).

Other virulence factors of $B$. pseudomallei such as the surface polysaccharides have also been investigated as subunit vaccines especially two of the most well characterized B. pseudomallei surface polysaccharides i.e., the capsular polysaccharide (type I O-PS) and lipopolysaccharide (LPS) (type II O-PS) (Deshazer et al., 1998; Reckseidler et al., 2001; Nelson et al., 2004). Passive immunizations with antibodies to the LPS or capsular polysaccharide were demonstrated to reduce lethality of infection in mice and diabetic rats suggesting that these polysaccharides are of immunological importance (Bryan et al., 1994; Jones et al., 2002). Nelson et al. (2004) suggested the LPS or capsular polysaccharide as potential vaccine candidates for B. pseudomallei as 


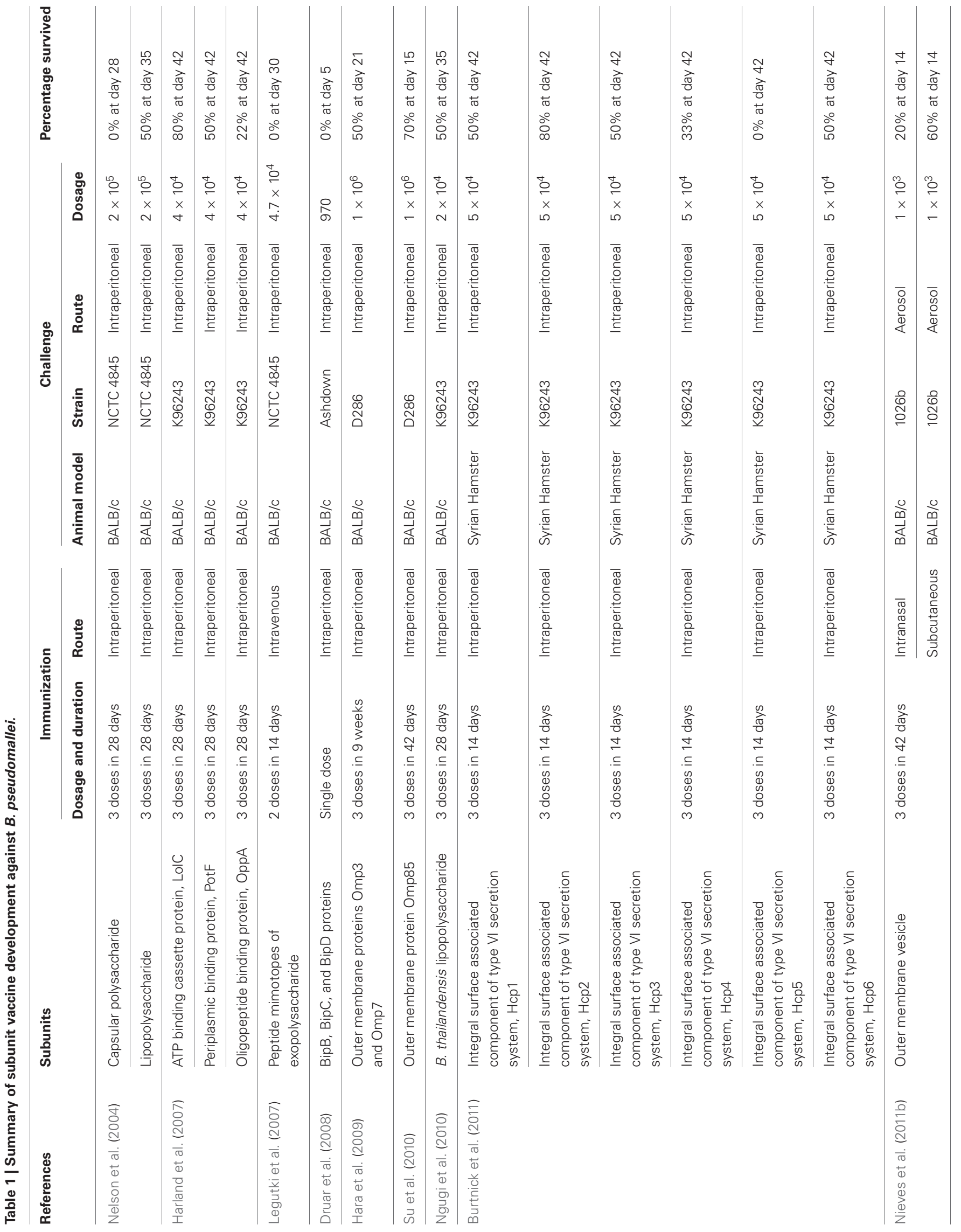


vaccination of the $\mathrm{BALB} / \mathrm{c}$ mice with these polysaccharides followed by an intraperitoneal route of challenge increased the mean time to death (MTTD) compared to the unvaccinated control which exhibited a MTTD of 2.6 days, with $100 \%$ mortality occurring by day 11. Lipolysaccharide provided the highest level of protection with a MTTD of 17.6 days and 50\% survival at day 35 followed by mice immunized with capsular polysaccharide with a MTTD of 10.5 days and $100 \%$ mortality by day 28 . Contrastingly, when the mice were challenged using an aerosol route, a slight increase of MTTD was observed as compared with the unvaccinated controls. Additionally, passive transfer of antibody from the immunized mice into the naïve mice also provided protection against subsequent challenges using $B$. pseudomallei.

In another study, since the LPS O-antigen of $B$. thailandensis and B. pseudomallei share a high similarity of $>90 \%$, the LPS O-antigen of $B$. thailandensis was used as a potential vaccine candidate. Ngugi et al. (2010) demonstrated that vaccination using both $B$. thailandensis LPS and B. pseudomallei LPS induced comparable levels of partial of protection against $B$. pseudomalle $i$ infections. Vaccination with B. thailandensis LPS exhibited $50 \%$ survival of the mice at day 35 post-challenge with a MTTD of 32.8 days whereas vaccination using $B$. pseudomallei LPS exhibited $66 \%$ survival of mice with a MTTD of 31.5 days. The ability of using the LPS of $B$. thailandensis, the avirulent counterpart of B. pseudomallei to provide comparable levels of partial protection against melioidosis is applauded since extraction of LPS from $B$. thailandensis which is a BSL-2 pathogen pose lower costs and more importantly reduced safety risk compared to the extraction from B. pseudomallei.

Other subunit vaccine candidates comprising recombinant flagellin antigens, recombinant OMP, outer membrane vesicles (OMV) and peptide mimotypes have also been tested with various degree of protection against Burkholderia spp. infection (Chen et al., 2006b; Legutki et al., 2007; Hara et al., 2009; Su et al., 2010; Nieves et al., 2011a). However, no sterile immunity was reported using all these candidates (Table 1). Subunit vaccines should still be considered as potential vaccine candidates as many immunogenic virulence factors of Burkholderia species have not yet been evaluated for their protective effects (Mariappan et al., 2010; Vellasamy et al., 2011).

\section{Burkholderia mallei}

A recent study by Whitlock et al. (2011) achieved 37.5-87.5\% survival rate upon challenge by $B$. mallei when mice are immunized with recombinant antigen proteins. These protective antigen proteins were identified by expression library immunization. This method might serves as a model for mass screening of potential vaccine candidate.

\section{Burkholderia cepacia}

Virulence factors such as proteases, LPS core antigen, flagella antigens, exopolysaccharides, and elastase have been considered as targets for development of vaccine against $B$. cepacia infections. However, none of these antigens are thought to be protective (Doring and Hoiby, 1983; Fujita et al., 1990; Nelson et al., 1993). Recently, a carbohydrate-based potential vaccine has been described which is a trisaccharide based on the repeating unit of a polysaccharide in the LPS of a clinical isolate of B. cepacia. However, coupling of trisaccharide or unprotected trisaccharide with a T cell epitope has yet to be developed (Faure et al., 2007).

Using a murine model of chronic pulmonary infection with B. cepacia, Bertot et al. (2007) demonstrated that intranasal immunization with OMP can induce specific mucosal immune responses in the respiratory tract, which in turn enhances the clearance of $B$. cepacia and minimize lung inflammatory damage after bacterial challenge. In addition, they have also suggested that the OMP may provide cross-protection against other Bcc members. Immunoglobulin $\mathrm{G}$ antibodies to $B$. cepacia OMP have been detected in sera of CF patients colonized with both B. cepacia and $P$. aeruginosa, suggesting cross-reactivity between the OMPs of these organisms (Aronoff et al., 1991).

In addition, Makidon et al. (2010) confirmed the findings of Bertot et al. (2007) and demonstrated significant response to the $17 \mathrm{kDa}$ OmpA lipoprotein. In their study, it was found that immunized mice were protected against pulmonary colonization with $B$. cepacia and they have also identified a new immunodominant epitope, a $17 \mathrm{kDa}$ OmpA-like protein which is highly conserved between Burkholderia and Ralstonia spp. In addition, serum analysis showed robust IgG and mucosal secretory IgA immune responses in vaccinated versus control mice and this suggest that the antibodies had cross-neutralizing activity against Bcc. Makidon et al. (2010) have also suggested that the $17 \mathrm{kDa}$ OmpA-like protein shows potential for future vaccine development and provides a rational basis for vaccines using recombinant OMP mixed with nano-emulsion as an adjuvant.

More recently, 18 immunogenic proteins from $B$. cepacia culture supernatant that reacted with mice antibodies raised to B. cepacia inactivated whole bacteria, OMP, and culture filtrate antigen were suggested to be potential molecules as a diagnostic marker or putative candidates for development of vaccine and therapeutic intervention against $B$. cepacia infections (Mariappan et al., 2010). Additionally, secretory proteins of B. cepacia have been suggested as possible targets for the development of new strategies to control B. cepacia infection using agents that can block their release (Mariappan et al., 2011).

Metalloproteases are also being considered as potential effective candidates for vaccine development (Corbett et al., 2003). Furthermore, it was demonstrated that immunizations of mice using a conserved zinc metalloprotease peptide decreased the severity of B. cepacia infection and the lung damage was reduced by $50 \%$ on challenge with a $B$. cepacia strain after immunization with this peptide (Corbett et al., 2003). Additionally, BLAST analysis demonstrated that metalloprotease shared a $96 \%$ and above homology with the metalloprotease of $B$. pseudomallei K96243. Therefore, this protein has been suggested to be used to cover immunization for both B. cepacia and B. pseudomallei to cross-protect (Mariappan et al., 2010).

\section{LIVE ATTENUATED VACCINES}

Live vaccines have been widely used for vaccination against infectious diseases, such as tuberculosis, cholera, mumps, and measles. Previously, live attenuated vaccines were developed from attenuated strains which have undergone passages in laboratory conditions or immunologically related species/microorganism that 
does not use human as the target host. Live attenuated vaccines are able to replicate and are recognized as foreign by human body without causing any pathological or lethal effects. Empirical approaches used for live vaccines development are time-consuming and the basis of attenuation is usually undefined. The advancement of modern DNA recombinant technology enables researchers to specifically inactivate essential gene(s) involved in pathogenesis, which leads to the development of well-defined attenuated live vaccines (Clare and Dougan, 2004). Live attenuated vaccines are considered the most ideal vaccine with great advantage due to the ability to elicit wide range of immune responses. Burkholderia pathogens are cytosolic intracellular bacteria whereby the antigenic proteins present in the cytosol after endosomal escape will be processed by the proteasome in the endogenous pathway and presented to $\mathrm{CD}^{+} \mathrm{T}$ cells by class I major histocompatibility complex (MHC). In contrast, inactivated vaccines are generally unable to induce $\mathrm{CD} 8^{+}$cytotoxic $\mathrm{T}$ cell immunity, which is essential in clearing intracellular pathogens (Seder and Hill, 2000). Live attenuated vaccines require lesser or even only a dose of vaccination for long lasting immune protection and without the use of adjuvant.

\section{Burkholderia pseudomallei}

To date, genes involving capsular polysaccharide synthesis and amino acid synthesis pathways (for example, shikimic pathway, and branch chain amino acids synthesis) are the main targets for creating attenuated variant. Acapsular mutant of B. pseudomallei (strain 1E10) created by Atkins et al. (2002a) showed no immunization protective effect toward BALB/c mice challenged by B. pseudomallei strain 576 . The gmhA and $w c b J$ mutant strains which are defective in capsular polysaccharide synthesis were used to immunize BALB/c mice. The immunized mice were partially protected from $B$. pseudomallei challenge; however, sterile immunity was not achieved.

Several other genes involved in essential amino synthesis pathway have also been knocked-out and exhibited attenuated virulence. The $B$. pseudomallei strain 2D2 with defective acetolactate synthase (ilvI) gene identified from a mutant library are a branch amino acid auxotroph. Mice vaccinated with 2D2 survived longer compared to naïve mice when challenged with B. pseudomallei 576 and BRI but not protected toward Francisella tularensis challenge (Atkins et al., 2002b). In another study performed by Haque and his team (2006) using B. pseudomallei $2 \mathrm{D} 2$ as the vaccine model have demonstrated that vaccinated mice elicited $\mathrm{CD} 4^{+}$immune reaction as a protective mechanism against $B$. pseudomallei infections. With the same vaccination model, intranasal route of vaccination was shown to confer better protection toward pulmonary B. pseudomallei infection which was associated with higher production of interferon- $\gamma$ (IFN $\gamma$ ) compared to intraperitoneal administration (Easton et al., 2011). The same study also demonstrated that vaccination incorporated with intranasal $\mathrm{CpG}$ ODN treatment extended survival ability of vaccinated mice, highly reduced lung bacterial load and delayed onset of bacterial sepsis after challenge. Similarly, ilvI gene, phosphoserine aminotransferase (serC) (Rodrigues et al., 2006), dehydroquinate synthase (aroB) (Cuccui et al., 2007), chorismate synthase (aroC) (Srilunchang et al., 2009), and aspartate semialdehyde dehydrogenase (asd) (Norris et al., 2011a) genes have also been utilized as gene targets to develop amino acid auxotrophs for vaccination studies in melioidosis (Table 2).

The type 3 secretion system cluster 3 (TTSS3) (Stevens et al., 2004) encodes important virulence factors which are highly involved in B. pseudomallei pathogenesis (Lazar Adler et al., 2009). Based on this, a mutant defect in the translocator protein gene, bipD, was constructed by Stevens et al. (2004) for BALB/c mice immunization and the immunized mice exhibited partial protection against $B$. pseudomallei infections. Besides the genes involved in amino acid synthesis, polysaccharide synthesis, and T3SS, genes involved in purine synthesis pathway are also candidates for construction of live attenuated vaccines. The purN defective mutant strains were used for immunization in the study performed by Breitbach et al. (2008). Protection against B. pseudomallei challenge was demonstrated in immunized BALB/c mice (Breitbach et al., 2008) (Table 2). Another mutant strain created in the same study (purM-knock out strain) demonstrated dosagedependent protection whereby mice immunized with higher dosage of purM mutant exhibited better protection than that of lower dosage (Table 2).

Interestingly, B. pseudomallei strain CL04 (isolated from a chronic melioidosis patient) (Ulett et al., 2005) and NTCC 13179 (Barnes and Ketheesan, 2007) exhibited natural attenuated virulence and protection properties when immunized BALB/c mice were challenged with virulent B. pseudomallei strains (Table 2). However, CL04 and NTCC 13179 are wild type B. pseudomallei strains isolated from melioidosis patients and these strains are not suitable to be used as the live attenuated vaccine candidates.

\section{Burkholderia mallei}

Similar to B. pseudomallei, the mutant strain 1E10, an acapsular mutant of $B$. mallei (strain DD3008) exhibited no vaccination protection toward challenge against B. mallei ATCC 23344 (Deshazer et al., 2001). This might be due to the development of IgG $_{1}$ (Th2-like immunoglobulin) antibody response in vaccinated mice (Ulrich et al., 2005). B. mallei knockout strain of ilvI (strain ILV1) was also constructed in order to develop vaccines against $B$. mallei and to study the effect of vaccination on glanders. As reported by Ulrich and others (2005), B. mallei ILV1vaccinated mice developed $\mathrm{IgG}_{2}$ (Th1-like immunoglobulin) antibody response which conferred resistance toward $B$. mallei infection. However, ILV1 vaccination does not confer sterile immunity and the vaccinated mice developed splenomegaly following challenge with live bacteria (Table 3). Apart from the ilvI gene, gene knockouts for capsule production $(w c b B)$ and carboxyl-terminal protease-encoded gene (ctpA) also demonstrated attenuated virulence of $B$. mallei. Administration of the $w c b B$ and $c t p A$ knockout strains conferred protection against wild type $B$. mallei in vaccinated animal models (Table 3 ).

Despite accumulating data on live attenuated vaccines against B. pseudomallei and B. mallei, the analysis is rather complicated due to the different immunization protocols, wild type challenge dosages, route of administration, and animal model used. Therefore, the results are not comparable in order to determine the most suitable live attenuated vaccine candidate for use as potential Burkholderia vaccines (Sarkar-Tyson and Titball, 2010). 


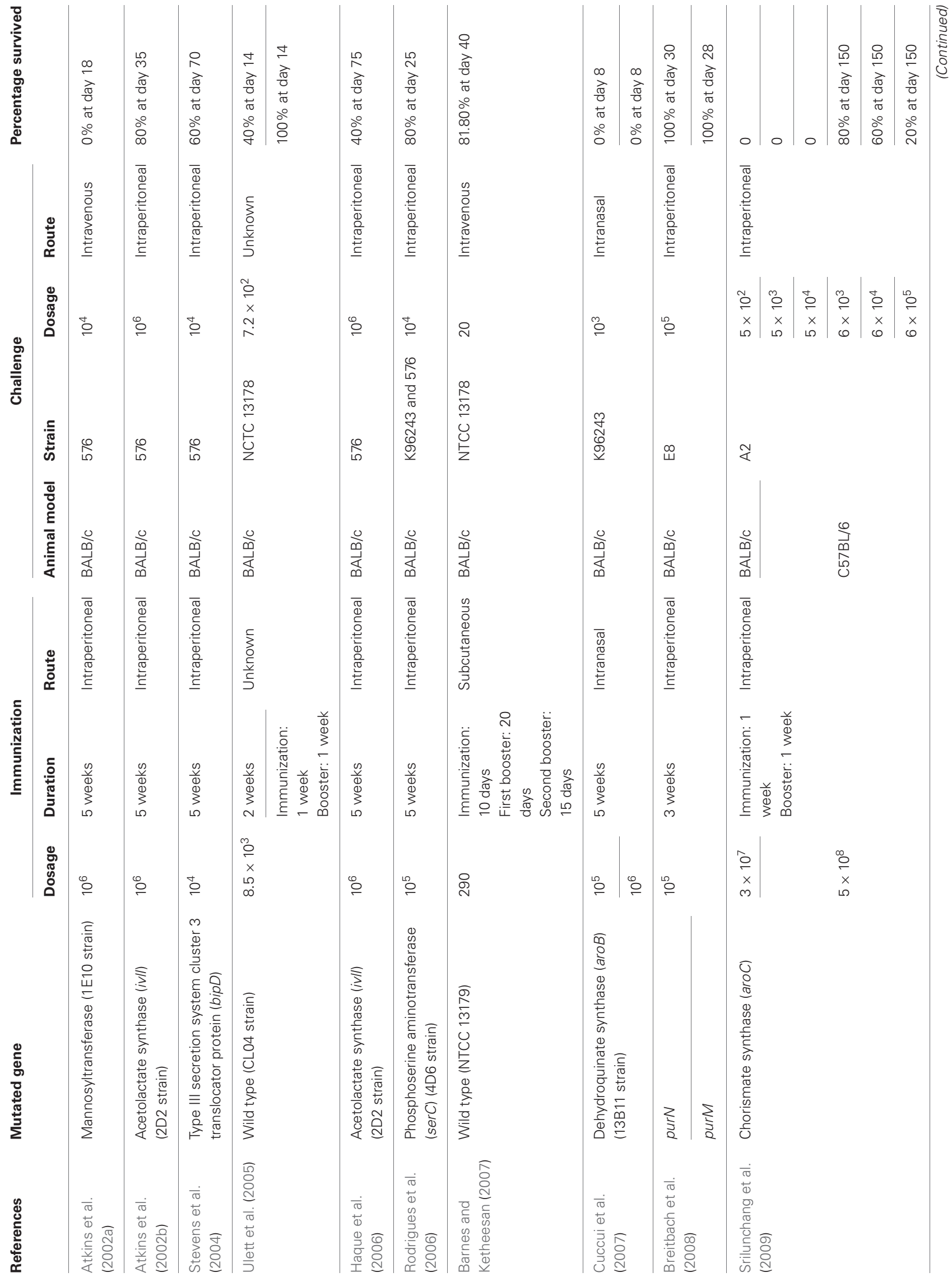




\section{KILLED WHOLE CELL VACCINES}

Killed whole cell vaccines are non-living pathogens which remain immunogenic for host immune system to recognize as "foreign." These vaccines have been widely used for the prevention of anthrax, Q fever, and whooping cough (Ada, 2001). This type of vaccine is known to induce a narrow range of immune responses due to the inability to replicate in the host. On the other hand, the inability to replicate is also a major advantage for the killed whole cell vaccines; making them an extremely safe prophylactic stimulation of the immune system and as such suitable for vaccinations on immunocompromised individuals. These vaccines are also good candidates for inducing humoral immunity to produce neutralizing antibodies. It is generally known that killed whole cell vaccines do not stimulate strong cellular-mediated immunity due to the fact that the antigens are not processed by an endogenous pathway and presented to the T cells by class I MHC. Hence, multiple doses of vaccination and adjuvants are required for long lasting protection (Ada, 2003). Experimental testing of the potency of kill whole cell vaccines in Burkholderia spp. has been investigated employing various animal models, administration and challenge routes, inactivation protocols, and adjuvants.

\section{B. pseudomallei}

Inactivated Burkholderia pathogens confer different degrees of protections toward B. pseudomallei and B. mallei infections. B. pseudomallei, B. mallei, and B. thailandensis are phylogenetically closely related and hence, cross protections are highly possible. Study conducted by Sarkar-Tyson et al. (2009) has demonstrated that immunization by heat-inactivated $B$. mallei and B. thailandensis conferred protection toward B. pseudomallei infections. In fact, BALB/c mice immunized by heat-inactivated B. mallei ATCC 23344 exhibited better protection (i.e., higher survival percentage and longer MTTD) against $B$. pseudomallei strain K96243 infection compared to mice immunized by heat-killed B. pseudomallei strain K96243 and 576. Barnes and Ketheesan (2007) also, demonstrated that heat-killed B. pseudomallei immunization via subcutaneous route does not protect immunized mice from subsequent challenge but heat-killed B. pseudomallei co-injected with culture filtrate antigen significantly increase the protection toward subsequent challenge (Table 4).

Other studies have demonstrated that the presence of capsular polysaccharide and LPS were able to affect the immunogenicity of heat-inactivated B. pseudomallei (Sarkar-Tyson et al., 2007). Heat-killed capsular polysaccharide mutant ( $w c b H$ knockout) and LPS $\mathrm{O}$ antigen mutants ( $w b i A$ knockout) demonstrated higher vaccination protection against $B$. pseudomallei $(70 \%$ and $80 \%$ after day 35 , respectively) in comparison to mice vaccinated with heat-killed putative type III O-polysaccharide mutant (BPSS0421 knockout) and putative type IV O-polysaccharide mutants (BPSS1833 knockout) in the study of Sarkar-Tyson and collaborators (2007) (Table 4). The authors have postulated that depletion of capsular polysaccharide and LPS might leads to the exposure of hidden immunogens or upregulation of the less abundant surface polysaccharides. The use of cationic liposomes complexed with non-coding plasmid DNA as mucosal adjuvant with heat-killed $B$. pseudomallei has also been found to increase the survival rate of challenged $\mathrm{BALB} / \mathrm{c}$ mice to $100 \%$ 
(after day 40) compared to BALB/c only immunized with heatkilled B. pseudomallei (Henderson et al., 2011) (Table 4).

Dendritic cells are strong professional antigen presenting cells (APC) which induce strong adaptive immunity, especially T cellsbased immunity. Therefore, delivering antigen-primed dendritic cells into human is a potential method to induce vaccinated protection. Thus, pulsing of inactivated B. pseudomallei into dendritic cells was performed and reported. Mice immunized by heat-killed B. pseudomallei pulsed dendritic cells demonstrated significant stronger cell-mediated immune responses compared to mice immunized by heat-killed $B$. pseudomallei. The addition of $\mathrm{CpG}$ ODN with heat-killed $B$. pseudomallei during priming of dendritic cells or as adjuvant demonstrated increase in the secretion of IFN $\gamma$ (indicating the stimulation of Th1 immune responses) and anti-B. pseudomallei antibody production (Healey et al., 2005; Elvin et al., 2006) (Table 4).

\section{Burkholderia mallei}

Amemiya et al. (2002), demonstrated that BALB/c mice immunized by heat-inactivated B. mallei strain ATCC 23344 with Alhydrogel as adjuvant showed mixed Th1- and Th2-like cytokine responses in spleenocytes and Th2-like IgG responses. However, these vaccinated mice were not protected from the B. mallei challenge. This study eventually led to the investigation of the protective effects conferred by co-administration of interleukin (IL) 12 with heat-killed B. mallei and Alhydrogel adjuvant. Incorporation of IL12 increased the secretion of IFN $\gamma$ and IL10 while at the same time increasing the production of anti-B. mallei IgG2. These collectively indicate that the Th1 response was stimulated in $\mathrm{BALB} / \mathrm{C}$ mice challenged with live $B$. mallei. Th1 immune response elicited after inclusion of IL12 in the vaccination regime has conferred partial protection against $B$. mallei challenged via intraperitoneal route (Amemiya et al., 2006). However, studies reported by Whitlock and others (2008) demonstrated that sterilizing immunity was not achieved in immunized BALB/c. Interestingly, the greatest protection against $B$. mallei was not conferred by heat-inactivated bacteria from the same species but from a closely related species as demonstrated by Sarkar-Tyson et al. (2009). They observed higher resistance exhibited by BALB/c mice immunized with heat-inactivated B. pseudomallei K96243 compared to the BALB/c mice immunized with heat-inactivated B. mallei ATCC 23344 when challenged with B. mallei ATCC 23344 (Table 5).

\section{DNA VACCINES}

Immunization using DNA is used to efficiently stimulate humoral and cellular immune responses to protein antigens. When a genetic material is directly injected into the host, a small amount of the host's cells will express the related gene products. This inappropriate gene expression within the host has important immunological consequences, resulting in the specific immune activation of the host against the gene delivered antigen (Koprowski and Weiner, 1998).

Currently the only DNA vaccine developed against any Burkholderia spp. utilizes the fliC gene of B. pseudomallei. Chen et al. (2006b) demonstrated that mice vaccinated with plasmid DNA using mammalian expression vector pcDNA3/fliC gene 


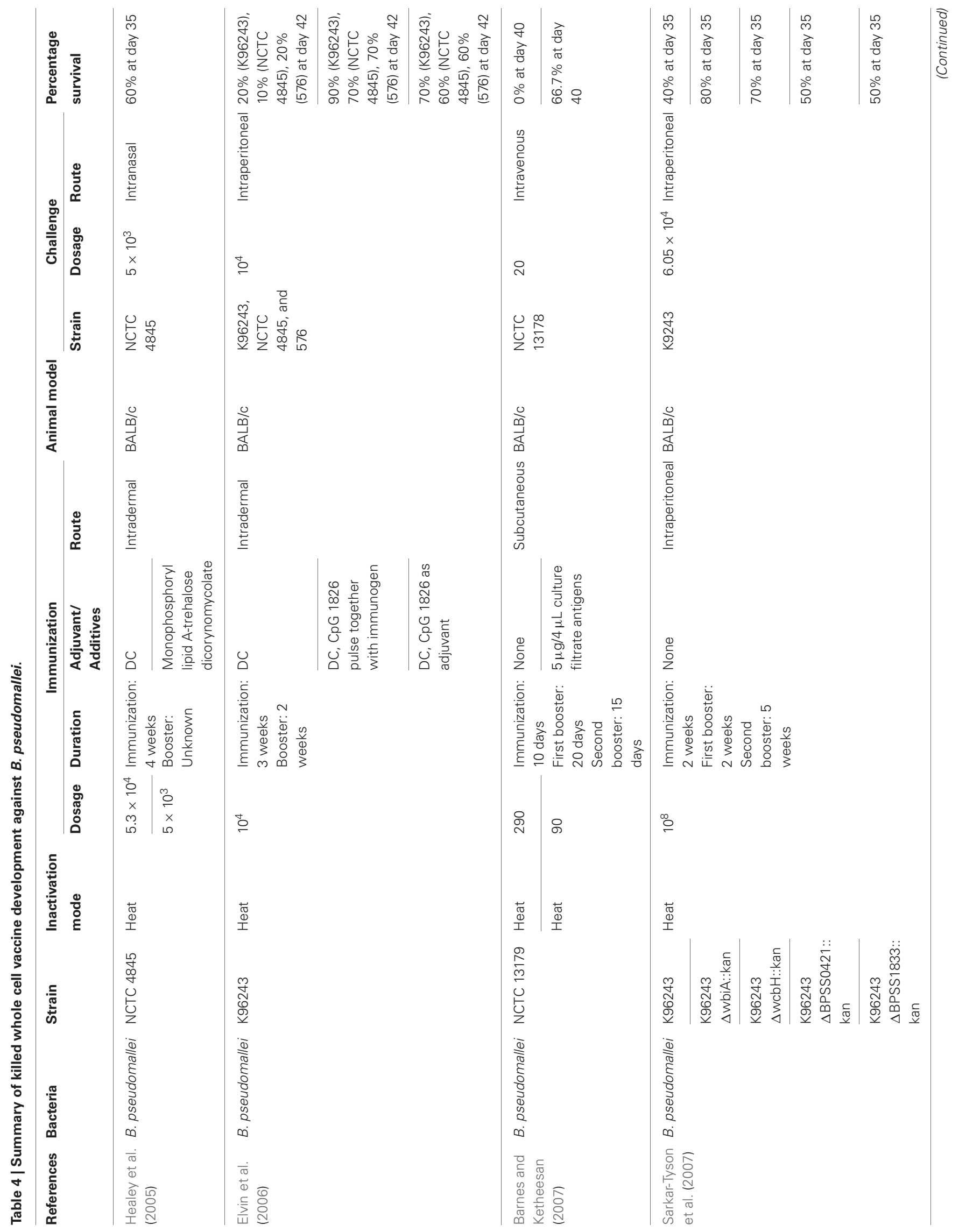




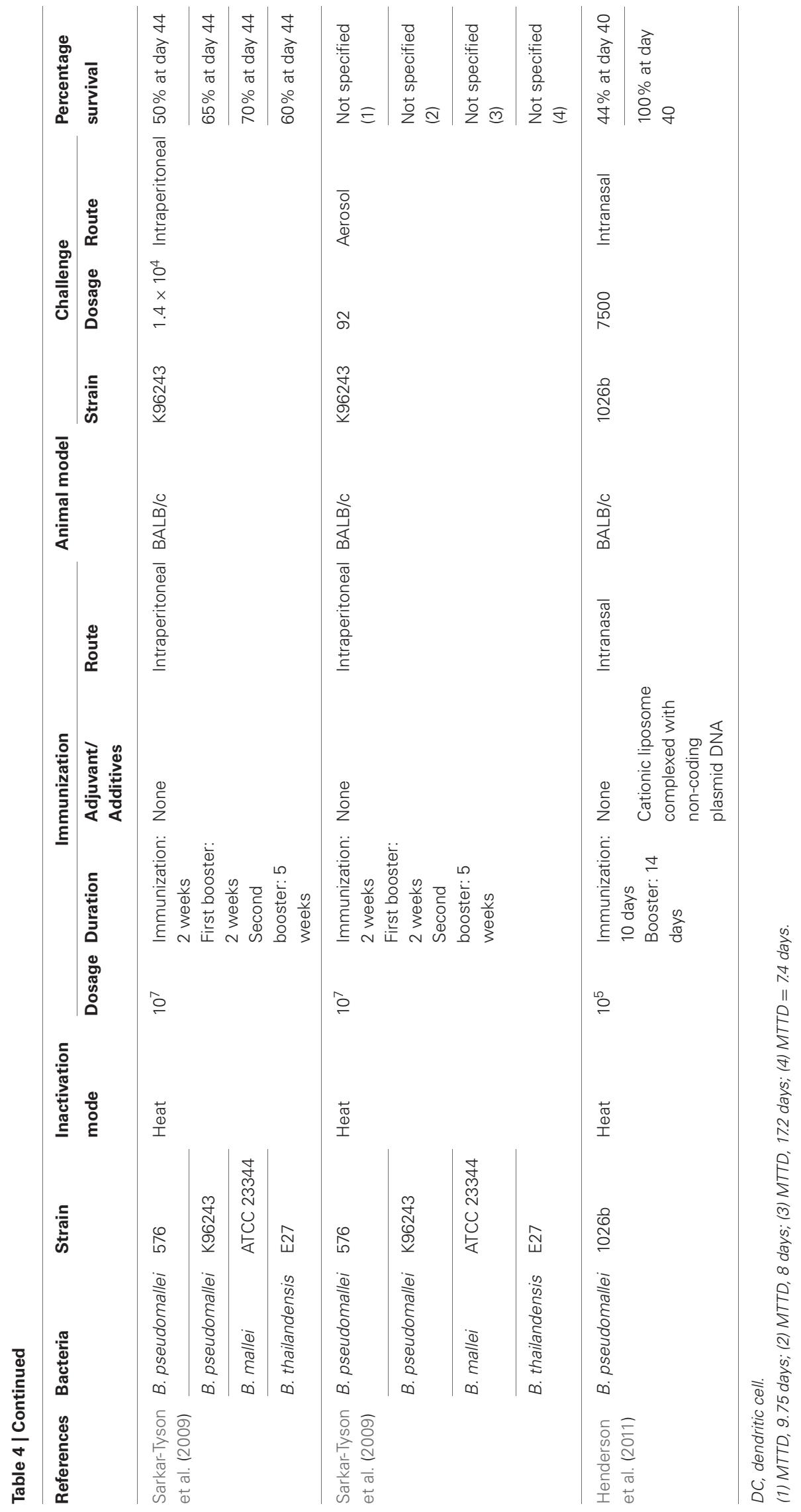




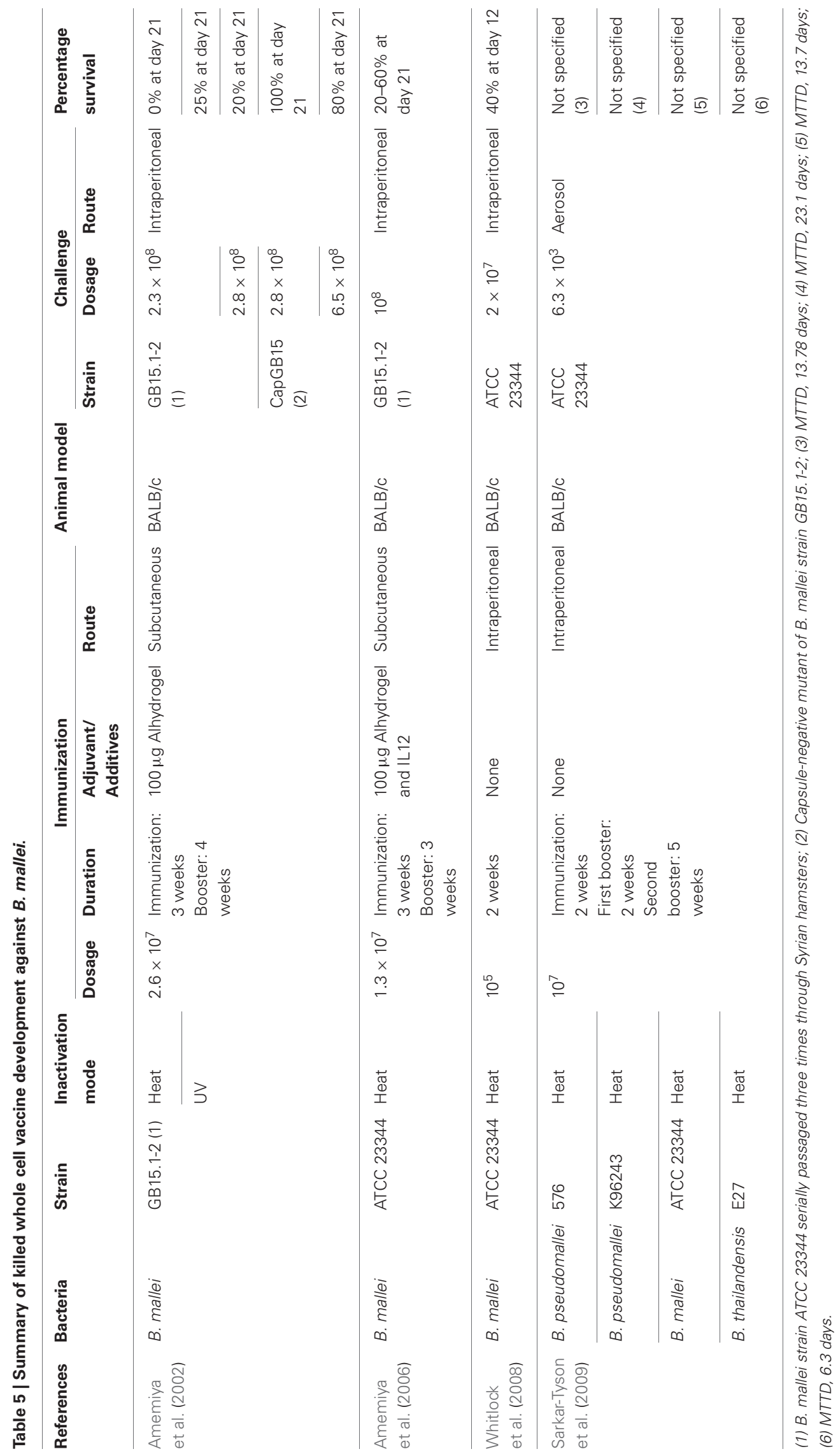


survived better than mice vaccinated with recombinant FliC protein ( $83 \%$ vs. 50\%). Plasmid DNA encoding the flagellin gene was able to generate high levels of specific antibodies in which upregulation of IFN- $\gamma$ and increase in the IgG2a/IgG1 ratio was observed. However, generally the DNA vaccines were reported to induce weaker immune response in humans (Liu, 2011). It was demonstrated that immunization of mice with priming of immuno-stimulatory $\mathrm{CpG}$ motifs and pcDNA3/fliC further enhances the survivability to $93.3 \%$ when challenged with B. pseudomallei (Chen et al., 2006a).

\section{POTENTIAL VACCINE APPROACHES}

When $\mathrm{BALB} / \mathrm{c}$ mice were immunized with heat-inactivated B. thailandensis significant delay in the MTTD post-challenged with $B$. pseudomallei compared to non-immunized BALB/c mice were observed. Therefore, $B$. thailandensis may be considered a potential vaccine candidate, following genetic modification in order to express the immunogenic proteins from B. pseudomallei and $B$. mallei. In addition, Iliukhin et al. (2004), demonstrated that immunized animal models conferred resistance to $B$. pseudomallei and $B$. mallei following subcutaneous administration of live attenuated $F$. tularensis. It was suggested that $F$. tularensis may also be considered as a potential candidate for Burkholderia vaccines development since it is also a cytoplasmic facultative intracellular bacteria, similar to Burkholderia pathogens.

To date, development of live attenuated vaccines for Burkholderia spp. has only exploited the knockout of one gene at a time using techniques such as genetic alterations of bacteria via transformation, conjugation, or transduction. Therefore, reversion from attenuated strain to wild-type strain can occur in the environment and hence a major concern in the use of live attenuated bacteria as vaccine candidates. Two or more independent site-specific knockout should be considered as demonstrated in S. typhi strain CVD 908-htrA and Shigella flexneri strain CVD 1207. This approach needs to be treated with caution as it may pose the risk of over attenuation leading to a reduced immunogenicity of the attenuated vaccine as demonstrated for S. typhi strain 541Ty (Clare and Dougan, 2004).

It is well-known that heat and chemical treatment on pathogens for killed whole cell vaccines poses risk of affecting the immunogenicity. An alternative approach to inactivate Gram-negative pathogens like Burkholderia spp. without affecting the immunogen epitopes is the creation of a bacterial ghost by employing PhiX174 E gene lytic mechanism. The lysis E gene encodes a hydrophobic protein which produces transmembrane channels and releases the cytoplasmic content of the pathogen. This leaves the empty bacterial cell envelop which retains the immunogenicity and is able to stimulate APCs for major histocompatibility presentation (Haslberger et al., 2000; Talebkhan et al., 2010). This technique has been exploited in a variety of Gram-negative bacterial vaccine development (Szostak et al., 1996). Since there are a number of lytic Burkholderia bacteriophages that have been reported, exploiting the next generation sequencing and bioinformatics techniques, a more sophisticated lysis system could be employed for the creation of bacterial ghost of Burkholderia pathogens, as tools for killed whole cell vaccine development.

\section{COST EFFECTIVENESS AND EFFICACY OF A Burkholderia VACCINE}

In a recent paper, Peacock et al. (2012) emphasized the importance of cost-effectiveness of vaccines against $B$. pseudomallei. The study demonstrated the need to produce cost savings or at least potential savings depending on the level of efficacy of the vaccine, vaccination coverage rates, the population's risk profile, the cost of the vaccine, and whether future medical costs for additional years of life gained were included in the calculations.

Vaccines intervention for the control of endemic Burkholderia spp. should also be targeted where the most reliable estimates of the incidence of Burkholderia spp. infections occur. The high-risk groups such as diabetics and those with chronic kidney or lung disease could be considered as primary targets for Burkholderia spp. vaccine trials. In addition, occupational risk populations which include farmers, construction workers, and military personnel also need to be considered as target groups. Taking the occupational and economic-based evaluation into consideration, there is a necessity for the vaccine to be used in a low income community since Burkholderia spp. infections are also known as the "poor man's disease."

Among the high-risk populations, in the community of an endemic area, vaccination against Burkholderia pathogens can be associated with less frequent hospitalizations and with direct savings in health care costs. Overall, this will reduce the burden of the government in terms of health care cost. Reduction in disease severity alone would be predicted to improve outcome in view of the high mortality rate. However, one disadvantage may be that generating protective immunity in individuals with such underlying diseases may be difficult to achieve since several Burkholderia spp. infections spread from person-to-person. Emergency measures should be taken as part of the biodefense efforts by focusing on increasing the awareness amongst the medical community, improving the diagnostic capabilities and preparation of national response protocols. It has been suggested that vaccinating the risk group against Burkholderia spp. infections is more cost effective than many other preventive and therapeutic interventions (Peacock et al., 2012).

\section{FUTURE DIRECTION}

Despite different studies and strategies being used to identify effective vaccine candidates for Burkholderia spp., to date, no reliable and conveniently measured correlates of vaccineinduced efficacy against these bacteria and/or other intracellular pathogens have been identified. Most importantly, researchers have been unable to identify and measure the immune responses that may be used to predict vaccines that will protect against the intracellular pathogens. While some of the vaccine candidates are able to induce substantial humoral response, some lacked the ability to evoke strong cellular immune responses or the ability to protect against infection with the Burkholderia spp. Perhaps, better understanding of the specific mechanisms by which members of the Burkholderia spp. subvert host defenses and survive intracellularly will provide a stronger platform for identification of an effective vaccine candidate. Another limiting factor is the difficulties in generating protective immunity in immunocompromised individuals with underlying diseases such as diabetes 
and chronic lung disease may be difficult to achieve. Such correlation would extensively aid in the design of new vaccines for Gramnegative intracellular pathogens in general and Burkholderia spp. in specific.

\section{REFERENCES}

Aaron, S. D., Ferris, W., Henry, D. A., Speert, D. P., and Macdonald, N. E. (2000). Multiple combination bactericidal antibiotic testing for patients with cystic fibrosis infected with Burkholderia cepacia. Am. J. Respir. Crit. Care Med. 161, 1206-1212.

Ada, G. (2001). Vaccines and vaccination. N. Engl. J. Med. 345, 1042-1053.

Ada, G. (2003). Overview of vaccines. Methods Mol. Med. 87, 1-17.

Amemiya, K., Bush, G. V., Deshazer, D., and Waag, D. M. (2002). Nonviable Burkholderia mallei induces a mixed Th1- and Th2-like cytokine response in $\mathrm{BALB} / \mathrm{c}$ mice. Infect. Immun. 70, 2319-2325.

Amemiya, K., Meyers, J. L., Trevino, S. R., Chanh, T. C., Norris, S. L., and Waag, D. M. (2006). Interleukin12 induces a Thl-like response to Burkholderia mallei and limited protection in BALB/c mice. Vaccine 24, 1413-1420.

Aronoff, S. C., Quinn, F. J. Jr., and Stern, R. C. (1991). Longitudinal serum IgG response to Pseudomonas cepacia surface antigens in cystic fibrosis. Pediatr. Pulmonol. 11, 289-293.

Atkins, T., Prior, R., Mack, K., Russell, P., Nelson, M., Prior, J., et al. (2002a). Characterisation of an acapsular mutant of Burkholderia pseudomallei identified by signature tagged mutagenesis. J. Med. Microbiol. 51, 539-547.

Atkins, T., Prior, R. G., Mack, K., Russell, P., Nelson, M., Oyston, P. C., et al. (2002b). A mutant of Burkholderia pseudomallei, auxotrophic in the branched chain amino acid biosynthetic pathway, is attenuated and protective in a murine model of melioidosis. Infect. Immun. 70, 5290-5294.

Bandara, A. B., Deshazer, D., Inzana, T. J., Sriranganathan, N., Schurig, G. G., and Boyle, S. M. (2008). A disruption of ctpA encoding carboxy-terminal protease attenuates Burkholderia mallei and induces partial protection in CD1 mice. Microb. Pathog. 45, 207-216.

Barnes, J. L., and Ketheesan, N. (2007). Development of protective immunity in a murine model of melioidosis is influenced by the source of
Burkholderia pseudomallei antigens. Immunol. Cell Biol. 85, 551-557.

Bertot, G. M., Restelli, M. A., Galanternik, L., Aranibar Urey, R. C., Valvano, M. A., and Grinstein, S. (2007). Nasal immunization with Burkholderia multivorans outer membrane proteins and the mucosal adjuvant adamantylamide dipeptide confers efficient protection against experimental lung infections with $B$. multivorans and B. cenocepacia. Infect. Immun. 75 , 2740-2752.

Boddey, J. A., Day, C. J., Flegg, C. P., Ulrich, R. L., Stephens, S. R., Beacham, I. R., et al. (2007). The bacterial gene lfpA influences the potent induction of calcitonin receptor and osteoclast-related genes in Burkholderia pseudomallei-induced TRAP-positive multinucleated giant cells. Cell. Microbiol. 9, 514-531.

Bondi, S. K., and Goldberg, J. B. (2008). Strategies toward vaccines against Burkholderia mallei and Burkholderia pseudomallei. Expert Rev. Vaccines 7, 1357-1365.

Breitbach, K., Kohler, J., and Steinmetz, I. (2008). Induction of protective immunity against Burkholderia pseudomallei using attenuated mutants with defects in the intracellular life cycle. Trans. R. Soc. Trop. Med. Hyg. 102(Suppl. 1), S89-S94.

Breitbach, K., Rottner, K., Klocke, S., Rohde, M., Jenzora, A., Wehland, J., et al. (2003). Actin-based motility of Burkholderia pseudomallei involves the Arp 2/3 complex, but not $\mathrm{N}$-WASP and Ena/VASP proteins. Cell. Microbiol. 5, 385-393.

Brett, P. J., Deshazer, D., and Woods, D. E. (1997). Characterization of Burkholderia pseudomallei and Burkholderia pseudomallei-like strains. Epidemiol. Infect. 118, 137-148.

Brett, P. J., Deshazer, D., and Woods, D. E. (1998). Burkholderia thailandensis sp. nov., a Burkholderia pseudomallei-like species. Int. J. Syst. Bacteriol. 48(Pt 1), 317-320.

Bryan, L. E., Wong, S., Woods, D. E., Dance, D. A., and Chaowagul, W. (1994). Passive protection of diabetic rats with antisera specific for the polysaccharide portion of the lipopolysaccharide isolated from Pseudomonas pseudomallei. Can. J. Infect. Dis. 5, 170-178.

\section{ACKNOWLEDGMENTS}

Research in the authors' laboratory was supported by Ministry of Higher Education (MOHE), Malaysia under the High Impact Research (HIR)-MOHE project E000013-20001.
Burkholder, W. H. (1950). Sour skin, a bacterial rot of onion bulbs. Phytopathology 40, 115-118.

Burtnick, M. N., Brett, P. J., Harding, S. V., Ngugi, S. A., Ribot, W. J., Chantratita, N., et al. (2011). The cluster 1 type VI secretion system is a major virulence determinant in Burkholderia pseudomallei. Infect. Immun. 79, 1512-1525.

Chen, Y. S., Hsiao, Y. S., Lin, H. H., Liu, Y., and Chen, Y. L. (2006a). CpGmodified plasmid DNA encoding flagellin improves immunogenicity and provides protection against Burkholderia pseudomallei infection in $\mathrm{BALB} / \mathrm{c}$ mice. Infect. Immun. 74 , 1699-1705.

Chen, Y. S., Hsiao, Y. S., Lin, H. H., Yen, C. M., Chen, S. C., and Chen, Y. L. (2006b). Immunogenicity and antiBurkholderia pseudomallei activity in Balb/c mice immunized with plasmid DNA encoding flagellin. Vaccine 24, 750-758.

Cheng, A. C., Limmathurotsakul, D., Chierakul, W., Getchalarat, N., Wuthiekanun, V., Stephens, D. P., et al. (2007). A randomized controlled trial of granulocyte colony-stimulating factor for the treatment of severe sepsis due to melioidosis in Thailand. Clin. Infect. Dis. 45, 308-314.

Clare, S., and Dougan, G. (2004). "Live recombinant bacterial vaccines," in Novel Vaccination Strategies, ed S. H. E. Kaufmann (Weinheim: WileyVCH), 319-341.

Coenye, T., Laevens, S., Gillis, M., and Vandamme, P. (2001). Genotypic and chemotaxonomic evidence for the reclassification of Pseudomonas woodsii (Smith 1911) Stevens 1925 as Burkholderia andropogonis (Smith 1911) Gillis et al. 1995. Int. J. Syst. Evol. Microbiol. 51, 183-185.

Compant, S., Nowak, J., Coenye, T., Clement, C., and Ait Barka, E. (2008). Diversity and occurrence of Burkholderia spp. in the natural environment. FEMS Microbiol. Rev. $32,607-626$.

Corbett, C. R., Burtnick, M. N., Kooi, C., Woods, D. E., and Sokol, P. A. (2003). An extracellular zinc metalloprotease gene of Burkholderia cepacia. Microbiology 149, 2263-2271.

Cuccui, J., Easton, A., Chu, K. K., Bancroft, G. J., Oyston, P. C., Titball, R. W., et al. (2007). Development of signature-tagged mutagenesis in Burkholderia pseudomallei to identify genes important in survival and pathogenesis. Infect. Immun. 75, 1186-1195.

Cuccui, J., Milne, T. S., Harmer, N. George, A. J., Harding, S. V., Dean, R. E., et al. (2012). Characterization of the Burkholderia pseudomallei K96243 capsular polysaccharide I coding region. Infect. Immun. 80, 1209-1221.

Currie, B. (2009). "Burkholderia pseudomallei and Burkholderia mallei: Melioidosis and Glanders," in Mandell, Douglas, and Bennett's Principles and Practice of Infectious Diseases, eds G. L. Mandell, J. E. Bennett, and R. Dolin (Philadelphia, PA: Churchill Livingstone), 2869-2979.

Currie, B. J., Fisher, D. A., Howard, D. M., Burrow, J. N., Lo, D., SelvaNayagam, S., et al. (2000). Endemic melioidosis in tropical northern Australia: a 10-year prospective study and review of the literature. Clin. Infect. Dis. 31, 981-986.

Dance, D. A. (2002). Melioidosis. Curr. Opin. Infect. Dis. 15, 127-132.

Deshazer, D., Brett, P. J., and Woods, D. E. (1998). The type II Oantigenic polysaccharide moiety of Burkholderia pseudomallei lipopolysaccharide is required for serum resistance and virulence. Mol. Microbiol. 30, 1081-1100.

Deshazer, D., Waag, D. M., Fritz, D. L., and Woods, D. E. (2001). Identification of a Burkholderia mallei polysaccharide gene cluster by subtractive hybridization and demonstration that the encoded capsule is an essential virulence determinant. Microb. Pathog. 30, 253-269.

Doring, G., and Hoiby, N. (1983). Longitudinal study of immune response to Pseudomonas aeruginosa antigens in cystic fibrosis. Infect. Immun. 42, 197-201.

Druar, C., Yu, F., Barnes, J. L., Okinaka, R. T., Chantratita, N., Beg, S., et al. (2008). Evaluating Burkholderia pseudomallei Bip proteins as vaccines and Bip antibodies as detection agents. FEMS Immunol. Med. Microbiol. 52, 78-87.

Easton, A., Haque, A., Chu, K., Patel, N., Lukaszewski, R. A., Krieg, A. M., et al. (2011). Combining vaccination and postexposure CpG therapy 
provides optimal protection against lethal sepsis in a biodefense model of human melioidosis. J. Infect. Dis. 204, 636-644

Elkins, K. L., Burns, D. L., Schmitt, M. P., and Weir, J. P. (2004). "Vaccines against bioterror agents," in Novel Vaccination Strategies, ed A. F. Kaufmann (Weinheim: WileyVCH), 529-545.

Elvin, S. J., Healey, G. D., Westwood, A., Knight, S. C., Eyles, J. E., and Williamson, E. D. (2006). Protection against heterologous Burkholderia pseudomallei strains by dendritic cell immunization. Infect. Immun. 74, 1706-1711.

Estes, D. M., Dow, S. W., Schweizer, H. P., and Torres, A. G. (2010). Present and future therapeutic strategies for melioidosis and glanders. Expert Rev. Anti. Infect. Ther. 8, 325-338.

Faure, R., Shiao, T. C., Lagnoux, D., Giguere, D., and Roy, R. (2007). En route to a carbohydrate-based vaccine against Burkholderia cepacia. Org. Biomol. Chem. 5, 2704-2708.

Finkelstein, R. A., Atthasampunna, P., and Chulasamaya, M. (2000). Pseudomonas (Burkholderia) pseudomallei in Thailand, 1964-1967: geographic distribution of the organism, attempts to identify cases of active infection, and presence of antibody in representative sera. Am. J. Trop. Med. Hyg. 62, 232-239.

Fritz, D. L., Vogel, P., Brown, D. R., and Waag, D. M. (1999). The hamster model of intraperitoneal Burkholderia mallei (glanders). Vet. Pathol. 36, 276-291.

Fujita, J., Nelson, N. L., Daughton, D. M., Dobry, C. A., Spurzem, J. R., Irino, S., et al. (1990). Evaluation of elastase and antielastase balance in patients with chronic bronchitis and pulmonary emphysema. Am. Rev. Respir. Dis. 142, 57-62.

Gan, Y. H. (2005). Interaction between Burkholderia pseudomallei and the host immune response: sleeping with the enemy? J. Infect. Dis. 192, 1845-1850.

George, A. M., Jones, P. M., and Middleton, P. G. (2009). Cystic fibrosis infections: treatment strategies and prospects. FEMS Microbiol. Lett. 300, 153-164.

George, R. B., Cartier, Y., Casson, A. G., and Hernandez, P. (2006). Suppurative mediastinitis secondary to Burkholderia cepacia in a patient with cystic fibrosis. Can. Respir. J. 13, 215-218.

Govan, J. R., Brown, P. H., Maddison, J., Doherty, C. J., Nelson, J. W., Dodd, M., et al. (1993). Evidence for transmission of Pseudomonas cepacia by social contact in cystic fibrosis. Lancet 342, 15-19.

Haque, A., Chu, K., Easton, A., Stevens, M. P., Galyov, E. E., Atkins, T., et al. (2006). A live experimental vaccine against Burkholderia pseudomallei elicits CD4+ T cell-mediated immunity, priming $\mathrm{T}$ cells specific for 2 type III secretion system proteins. J. Infect. Dis. 194, 1241-1248.

Hara, Y., Mohamed, R., and Nathan, S. (2009). Immunogenic Burkholderia pseudomallei outer membrane proteins as potential candidate vaccine targets. PLoS ONE 4:e6496. doi: 10.1371/journal.pone.0006496

Harland, D. N., Chu, K., Haque, A., Nelson, M., Walker, N. J., Sarkar-Tyson, M., et al. (2007). Identification of a LolC homologue in Burkholderia pseudomallei, a novel protective antigen for melioidosis. Infect. Immun. 75, 4173-4180.

Haslberger, A. G., Kohl, G., Felnerova, D., Mayr, U. B., Furst-Ladani, S., and Lubitz, W. (2000). Activation, stimulation and uptake of bacterial ghosts in antigen presenting cells. J. Biotechnol. 83, 57-66.

Healey, G. D., Elvin, S. J., Morton, M., and Williamson, E. D. (2005). Humoral and cell-mediated adaptive immune responses are required for protection against Burkholderia pseudomallei challenge and bacterial clearance postinfection. Infect. Immun. 73, 5945-5951.

Heine, H. S., England, M. J., Waag, D. M., and Byrne, W. R. (2001). In vitro antibiotic susceptibilities of Burkholderia mallei (causative agent of glanders) determined by broth microdilution and E-test. Antimicrobial Agents Chemother. 45, 2119-2121.

Henderson, A., Propst, K., Kedl, R., and Dow, S. (2011). Mucosal immunization with liposome-nucleic acid adjuvants generates effective humoral and cellular immunity. Vaccine 29, 5304-5312.

Iliukhin, V. I., Plekhanova, N. G., Senina, T. V., Stanovaia, O. V., and Kislichkin, N. N. (2004). [Experimental study on the possibility of using live tularemia vaccine to increase resistance to heterologous infection disease]. $\mathrm{Zh}$. Mikrobiol. Epidemiol. Immunobiol. Mar-Apr, 38-42.

Jones, A. M., Dodd, M. E., Govan, J. R., Barcus, V., Doherty, C. J., Morris, J., et al. (2004). Burkholderia cenocepacia and Burkholderia multivorans: influence on survival in cystic fibrosis. Thorax 59, 948-951.

Jones, S. M., Ellis, J. F., Russell, P., Griffin, K. F., and Oyston, P. C.
(2002). Passive protection against Burkholderia pseudomallei infection in mice by monoclonal antibodies against capsular polysaccharide, lipopolysaccharide or proteins. J. Med. Microbiol. 51, 1055-1062.

Judy, B. M., Whitlock, G. C., Torres, A. G., and Estes, D. M. (2009). Comparison of the in vitro and in vivo susceptibilities of Burkholderia mallei to Ceftazidime and Levofloxacin. BMC Microbiol. 9:88. doi: 10.1186/1471-2180-9-88

Kanaphun, P., Thirawattanasuk, N. Suputtamongkol, Y., Naigowit, P., Dance, D. A., Smith, M. D. et al. (1993). Serology and carriage of Pseudomonas pseudomallei: a prospective study in 1000 hospitalized children in northeast Thailand. J. Infect. Dis. 167, 230-233.

Kenny, D. J., Russell, P., Rogers, D., Eley, S. M., and Titball, R. W. (1999). In vitro susceptibilities of Burkholderia mallei in comparison to those of other pathogenic Burkholderia spp. Antimicrobial Agents Chemother. 43, 2773-2775.

Kespichayawattana, W., Rattanachetkul, S., Wanun, T., Utaisincharoen, P., and Sirisinha, S. (2000) Burkholderia pseudomallei induces cell fusion and actin-associated membrane protrusion: a possible mechanism for cell-to-cell spreading. Infect. Immun. 68 , 5377-5384.

Koprowski, H., and Weiner, D. B (1998). DNA vaccination/genetic vaccination. Curr. Top. Microbiol. Immunol. 226, V-XIII.

Lazar Adler, N. R., Govan, B. Cullinane, M., Harper, M., Adler B., and Boyce, J. D. (2009). The molecular and cellular basis of pathogenesis in melioidosis: how does Burkholderia pseudomallei cause disease? FEMS Microbiol. Rev. 33, 1079-1099.

Leelarasamee, A. (2004). Recent development in melioidosis. Curr. Opin. Infect. Dis. 17, 131-136.

Legutki, J. B., Nelson, M., Titball, R., Galloway, D. R., Mateczun, A., and Baillie, L. W. (2007). Analysis of peptide mimotopes of Burkholderia pseudomallei exopolysaccharide. Vaccine 25, 7796-7805.

Leitao, J. H., Sousa, S. A., Cunha, M. V., Salgado, M. J., MeloCristino, J., Barreto, M. C., et al. (2008). Variation of the antimicrobial susceptibility profiles of Burkholderia cepacia complex clonal isolates obtained from chronically infected cystic fibrosis patients: a five-year survey in the major Portuguese treatment center.
Eur. J. Clin. Microbiol. Infect. Dis. 27, 1101-1111.

Lessie, T. G., Hendrickson, W., Manning, B. D., and Devereux, R. (1996). Genomic complexity and plasticity of Burkholderia cepacia. FEMS Microbiol. Lett. 144, 117-128.

Liljeqvist, S., and Stahl, S. (1999). Production of recombinant subunit vaccines: protein immunogens, live delivery systems and nucleic acid vaccines. J. Biotechnol. 73, 1-33.

Liu, M. A. (2011). DNA vaccines: an historical perspective and view to the future. Immunol. Rev. 239 62-84.

Macdonald, K. L., and Speert, D. P. (2007). "Interactions of Burkholderia species with the phagocytic system," in Burkholderia: Molecular Microbiology and Genomics, eds T. Coenye and P. Vandamme (Wymondham: Horizon Bioscience), 111-127.

Makidon, P. E., Knowlton, J., Groom, J. V., 2nd, Blanco, L. P., Lipuma, J. J., Bielinska, A. U., et al. (2010). Induction of immune response to the $17 \mathrm{kDa}$ OMPA Burkholderia cenocepacia polypeptide and protection against pulmonary infection in mice after nasal vaccination with an OMP nanoemulsion-based vaccine. Med. Microbiol. Immunol. 199, 81-92.

Mann, T., Ben-David, D., Zlotkin, A., Shachar, D., Keller, N., Toren, A., et al. (2010). An outbreak of Burkholderia cenocepacia bacteremia in immunocompromised oncology patients. Infection 38, 187-194.

Mariappan, V., Vellasamy, K. M., Hashim, O. H., and Vadivelu, J. (2011). Profiling of Burkholderia cepacia secretome at mid-logarithmic and early-stationary phases of growth. PLoS ONE 6:e26518. doi: 10.1371/journal.pone.0026518

Mariappan, V., Vellasamy, K. M., Thimma, J. S., Hashim, O. H., and Vadivelu, J. (2010). Identification of immunogenic proteins from Burkholderia cepacia secretome using proteomic analysis. Vaccine 28, 1318-1324.

Marioni, G., Rinaldi, R., Ottaviano, G., Marchese-Ragona, R., Savastano, M., and Staffieri, A. (2006). Cervical necrotizing fasciitis: a novel clinical presentation of Burkholderia cepacia infection. J. Infect. 53, e219-e222.

Martin, D. W., and Mohr, C. D. (2000). Invasion and intracellular survival of Burkholderia cepacia. Infect. Immun. 68, 24-29.

Master, E. R., and Mohn, W. W. (1998). Psychrotolerant bacteria 
isolated from arctic soil that degrade polychlorinated biphenyls at low temperatures. Appl. Environ. Microbiol. 64, 4823-4829.

Moore, R. A., Reckseidler-Zenteno, S., Kim, H., Nierman, W., Yu, Y., Tuanyok, A., et al. (2004). Contribution of gene loss to the pathogenic evolution of Burkholderia pseudomallei and Burkholderia mallei. Infect. Immun. 72, 4172-4187.

Nelson, J. W., Butler, S. L., Brown, P. H., Greening, A. P., and Govan, J. R. (1993). Serum IgG and sputum IgA antibody to core lipopolysaccharide antigen from Pseudomonas cepacia in patients with cystic fibrosis. J. Med. Microbiol. 39, 39-47.

Nelson, M., Prior, J. L., Lever, M. S., Jones, H. E., Atkins, T. P., and Titball, R. W. (2004). Evaluation of lipopolysaccharide and capsular polysaccharide as subunit vaccines against experimental melioidosis. J. Med. Microbiol. 53, 1177-1182.

Ngugi, S. A., Ventura, V. V., Qazi, O., Harding, S. V., Kitto, G. B., Estes, D. M., et al. (2010). Lipopolysaccharide from Burkholderia thailandensis E264 provides protection in a murine model of melioidosis. Vaccine 28, 7551-7555.

Nieves, I. U., Geddes, C. C., Miller, E. N., Mullinnix, M. T., Hoffman, R. W., Fu, Z., et al. (2011a). Effect of reduced sulfur compounds on the fermentation of phosphoric acid pretreated sugarcane bagasse by ethanologenic Escherichia coli. Bioresour. Technol. 102, 5145-5152.

Nieves, W., Asakrah, S., Qazi, O., Brown, K. A., Kurtz, J., Aucoin, D. P., et al. (2011b). A naturally derived outer-membrane vesicle vaccine protects against lethal pulmonary Burkholderia pseudomallei infection. Vaccine 29, 8381-8389.

Norris, M. H., Propst, K. L., Kang, Y., Dow, S. W., Schweizer, H. P., and Hoang, T. T. (2011a). The Burkholderia pseudomallei \{Delta\}asd mutant exhibits attenuated intracellular infectivity and imparts protection against acute inhalation melioidosis in mice. Infect. Immun. 79, 4010-4018.

Norris, M. H., Propst, K. L., Kang, Y., Dow, S. W., Schweizer, H. P., and Hoang, T. T. (2011b). The Burkholderia pseudomallei Deltaasd mutant exhibits attenuated intracellular infectivity and imparts protection against acute inhalation melioidosis in mice. Infect. Immun. 79, 4010-4018.

Parke, J. L., and Gurian-Sherman, D. (2001). Diversity of the
Burkholderia cepacia complex and implications for risk assessment of biological control strains. Annu. Rev. Phytopathol. 39, 225-258.

Patel, N., Conejero, L., De Reynal, M., Easton, A., Bancroft, G. J., and Titball, R. W. (2011). Development of vaccines against Burkholderia pseudomallei. Front. Microbiol. 2:198. doi: 10.3389/fmicb.2011.00198

Peacock, S. J., Limmathurotsakul, D., Lubell, Y., Koh, G. C., White, L. J., Day, N. P., et al. (2012). Melioidosis vaccines: a systematic review and appraisal of the potential to exploit biodefense vaccines for public health purposes. PLoS Negl. Trop. Dis. 6:e1488. doi: 10.1371/journal.pntd.0001488

Puthucheary, S. D. (2009). Melioidosis in Malaysia. Med. J. Malaysia 64, 266-274.

Reckseidler, S. L., Deshazer, D., Sokol, P. A., and Woods, D. E. (2001). Detection of bacterial virulence genes by subtractive hybridization: identification of capsular polysaccharide of Burkholderia pseudomallei as a major virulence determinant. Infect. Immun. 69, 34-44.

Rodrigues, F., Sarkar-Tyson, M., Harding, S. V., Sim, S. H., Chua, H. H., Lin, C. H., et al. (2006). Global map of growth-regulated gene expression in Burkholderia pseudomallei, the causative agent of melioidosis. J. Bacteriol. 188, 8178-8188.

Sarkar-Tyson, M., Smither, S. J., Harding, S. V., Atkins, T. P., and Titball, R. W. (2009). Protective efficacy of heat-inactivated $B$. thailandensis, B. mallei or B. pseudomallei against experimental melioidosis and glanders. Vaccine 27, 4447-4451.

Sarkar-Tyson, M., Thwaite, J. E., Harding, S. V., Smither, S. J., Oyston, P. C., Atkins, T. P., et al. (2007). Polysaccharides and virulence of Burkholderia pseudomallei. J. Med. Microbiol. 56, 1005-1010.

Sarkar-Tyson, M., and Titball, R. W. (2010). Progress toward development of vaccines against melioidosis: a review. Clin. Ther. 32, 1437-1445.

Seder, R. A., and Hill, A. V. (2000). Vaccines against intracellular infections requiring cellular immunity. Nature 406, 793-798.

Smith, M. D., Angus, B. J., Wuthiekanun, V., and White, N. J. (1997). Arabinose assimilation defines a nonvirulent biotype of Burkholderia pseudomallei. Infect. Immun. 65, 4319-4321.
Srilunchang, T., Proungvitaya, T., Wongratanacheewin, S., Strugnell, R., and Homchampa, P. (2009). Construction and characterization of an unmarked aroC deletion mutant of Burkholderia pseudomallei strain A2. Southeast Asian J. Trop. Med. Public Health 40, 123-130.

Srinivasan, A., Kraus, C. N., Deshazer, D., Becker, P. M., Dick, J. D., Spacek, L., et al. (2001). Glanders in a military research microbiologist. $N$. Engl. J. Med. 345, 256-258.

Stevens, M. P., Haque, A., Atkins, T., Hill, J., Wood, M. W., Easton, A., et al. (2004). Attenuated virulence and protective efficacy of a Burkholderia pseudomallei bsa type III secretion mutant in murine models of melioidosis. Microbiology 150, 2669-2676.

Stevens, M. P., Stevens, J. M., Jeng, R. L., Taylor, L. A., Wood, M. W., Hawes, P., et al. (2005). Identification of a bacterial factor required for actinbased motility of Burkholderia pseudomallei. Mol. Microbiol. 56, 40-53.

$\mathrm{Su}$, Y. C., Wan, K. L., Mohamed, R., and Nathan, S. (2010). Immunization with the recombinant Burkholderia pseudomallei outer membrane protein Omp85 induces protective immunity in mice. Vaccine 28 , 5005-5011.

Sun, G. W., Lu, J., Pervaiz, S., Cao, W. P., and Gan, Y. H. (2005) Caspase-1 dependent macrophage death induced by Burkholderia pseudomallei. Cell. Microbiol. 7, 1447-1458.

Suparak, S., Kespichayawattana, W., Haque, A., Easton, A., Damnin, S., Lertmemongkolchai, G., et al. (2005). Multinucleated giant cell formation and apoptosis in infected host cells is mediated by Burkholderia pseudomallei type III secretion protein BipB. J. Bacteriol. 187, 6556-6560.

Szostak, M. P., Hensel, A., Eko, F. O., Klein, R., Auer, T., Mader, H., et al. (1996). Bacterial ghosts: non-living candidate vaccines. J. Biotechnol. 44, 161-170.

Talebkhan, Y., Bababeik, M., Esmaeili, M., Oghalaei, A., Saberi, S., Karimi, Z., et al. (2010). Helicobacter pylori bacterial ghost containing recombinant Omp18 as a putative vaccine. J. Microbiol. Methods 82, 334-337.

Titball, R. W., Russell, P., Cuccui, J., Easton, A., Haque, A., Atkins, T., et al. (2008). Burkholderia pseudomallei: animal models of infection. Trans. R. Soc. Trop. Med. Hyg. 102(Suppl. 1), S111-S116.

Ulett, G. C., Labrooy, J. T., Currie, B. J., Barnes, J. L., and Ketheesan, N.
(2005). A model of immunity to Burkholderia pseudomallei: unique responses following immunization and acute lethal infection. Microbes Infect. 7, 1263-1275.

Ulrich, R. L., Amemiya, K., Waag, D. M., Roy, C. J., and Deshazer, D. (2005). Aerogenic vaccination with a Burkholderia mallei auxotroph protects against aerosolinitiated glanders in mice. Vaccine 23, 1986-1992.

Ussery, D. W., Kiil, K., Lagesen, K., Sicheritz-Ponten, T., Bohlin, J., and Wassenaar, T. M. (2009). The genus Burkholderia: analysis of 56 genomic sequences. Genome Dyn. 6, 140-157.

Vadivelu, J., Puthucheary, S. D., Gendeh, G. S., and Parasakthi, N. (1995). Serodiagnosis of melioidosis in Malaysia. Singapore Med. J. 36, 299-302.

Vandamme, P., Govan, J., and Lipuma, J. (2007). "Diversity and role of Burkholderia spp.," in Burkholderia: Molecular Microbiology and Genomics, eds T. Coenye and P. Vandamme (Norfolk: Horizon Bioscience), 1-28.

Vandamme, P., Holmes, B., Vancanneyt, M., Coenye, T., Hoste, B., Coopman, R., et al. (1997). Occurrence of multiple genomovars of Burkholderia cepacia in cystic fibrosis patients and proposal of Burkholderia multivorans sp. nov. Int. J. Syst. Bacteriol. 47, 1188-1200.

Vandamme, P., Mahenthiralingam, E., Holmes, B., Coenye, T., Hoste, B., De Vos, P., et al. (2000). Identification and population structure of Burkholderia stabilis sp. nov. (formerly Burkholderia cepacia genomovar IV). J. Clin. Microbiol. 38, 1042-1047.

Vanlaere, E., Baldwin, A., Gevers, D. Henry, D., De Brandt, E., Lipuma, J. J., et al. (2009). Taxon, K, a complex within the Burkholderia cepacia complex, comprises at least two novel species, Burkholderia contaminans sp. nov. and Burkholderia lata sp. nov. Int. J. Syst. Evol. Microbiol. 59, 102-111.

Vanlaere, E., Lipuma, J. J., Baldwin, A., Henry, D., De Brandt, E., Mahenthiralingam, E., et al. (2008). Burkholderia latens sp. nov., Burkholderia diffusa sp. nov., Burkholderia arboris sp. nov., Burkholderia seminalis sp. nov. and Burkholderia metallica sp. nov., novel species within the Burkholderia cepacia complex. Int. J. Syst. Evol. Microbiol. 58, 1580-1590.

Vasu, C., Vadivelu, J., and Puthucheary, S. D. (2003). The humoral immune 
response in melioidosis patients during therapy. Infection 31, 24-30.

Vellasamy, K. M., Mariappan, V., Hashim, O. H., and Vadivelu, J. (2011). Identification of immunoreactive secretory proteins from the stationary phase culture of Burkholderia pseudomallei. Electrophoresis 32, 310-320.

Vial, L., Groleau, M. C., Dekimpe, V., and Deziel, E. (2007). Burkholderia diversity and versatility: an inventory of the extracellular products. J. Microbiol. Biotechnol. 17, 1407-1429.

Warawa, J., and Woods, D. E. (2005). Type III secretion system cluster 3 is required for maximal virulence of Burkholderia pseudomallei in a hamster infection model. FEMS Microbiol. Lett. 242, 101-108.

Wheelis, M. (1998). First shots fired in biological warfare. Nature 395, 213.

Whitlock, G. C., Lukaszewski, R. A., Judy, B. M., Paessler, S., Torres, A. G., and Estes, D. M. (2008). Host immunity in the protective response to vaccination with heat-killed Burkholderia mallei. BMC Immunol. 9:55. doi: 10.1186/ 1471-2172-9-55

Whitlock, G. C., Robida, M. D., Judy, B. M., Qazi, O., Brown, K. A., Deeraksa, A., et al. (2011). Protective antigens against glanders identified by expression library immunization. Front. Microbiol. 2:227. doi: 10.3389/fmicb.2011.00227

Whitmore, A. (1913). An account of a glanders-like disease occurring in Rangoon. J. Hyg. (Lond.) 13, 1-34.1.

Whitmore, A., and Krishnaswami, C. S. (2012). An account of the discovery of a hitherto undescribed infective disease occurring among the population of Rangoon. Indian Med. Gazette 92, 262-267.

Wiersinga, W. J., and Van Der Poll, T. (2009). Immunity to Burkholderia pseudomallei. Curr. Opin. Infect. Dis. 22, 102-108.

Woods, D. E., and Sokol, P. A. (2006). "The genus Burkholderia" in
The Prokaryotes, eds M. Dworkin, S. Falkow, E. Rosenberg, K.-E. Schleifer, and E. Stackebrandt (New York, NY: Springer), 848-860. Wuthiekanun, V., Pheaktra, N., Putchhat, H., Sin, L., Sen, B., Kumar, V., et al. (2008). Burkholderia pseudomallei antibodies in children, Cambodia. Emerging Infect. Dis. 14, 301-303.

Yabuuchi, E., Kosako, Y., Oyaizu, H. Yano, I., Hotta, H., Hashimoto, Y., et al. (1992). Proposal of Burkholderia gen. nov. and transfer of seven species of the genus Pseudomonas homology group II to the new genus, with the type species Burkholderia cepacia (Palleroni and Holmes 1981) comb. nov. Microbiol. Immunol. 36, 1251-1275.

Yakushi, T., Masuda, K., Narita, S., Matsuyama, S., and Tokuda, H. (2000). A new ABC transporter mediating the detachment of lipid-modified proteins from membranes. Nat. Cell Biol. 2, 212-218.
Conflict of Interest Statement: The authors declare that the research was conducted in the absence of any commercial or financial relationships that could be construed as a potential conflict of interest.

Received: 10 August 2012; accepted: 20 January 2013; published online: 05 February 2013.

Citation: Choh L-C, Ong G-H, Vellasamy KM, Kalaiselvam K, Kang W-T, Al-Maleki AR, Mariappan $V$ and Vadivelu J (2013) Burkholderia vaccines: are we moving forward? Front. Cell. Inf. Microbio. 3:5. doi: 10.3389/fcimb 2013.00005

Copyright (C) 2013 Choh, Ong, Vellasamy, Kalaiselvam, Kang, AlMaleki, Mariappan and Vadivelu. This is an open-access article distributed under the terms of the Creative Commons Attribution License, which permits use, distribution and reproduction in other forums, provided the original authors and source are credited and subject to any copyright notices concerning any third-party graphics etc. 